\title{
The Timing of Genital Surgery in Somatic Intersexuality: Surveys of Patients' Preferences
}

\author{
Heino F.L. Meyer-Bahlburg
}

New York State Psychiatric Institute, and Department of Psychiatry, Vagelos College of Physicians \& Surgeons of Columbia University, New York, NY, USA

\section{Keywords}

Somatic intersexuality - Disorders of sex development · Genital surgery · Timing of genital surgery · Patients' opinions

\begin{abstract}
In recent years, intersex advocates, medical ethicists, and lawmakers have increasingly demanded a delay of genital surgery that is not acutely medically necessary in patients with somatic intersexuality to the age of consent. This study provides a review of published surveys of affected patients' own opinions on this issue. In part with search of PubMed 2000-2021, 10 pertinent surveys of patients were identified: 3 from the USA; 4 from European countries; and one each from Brazil, China, and Malaysia. All were based on samples of clinic patients, most of whom had previously undergone genital surgery. The majority of both $X X$ and $X Y$ patients with somatic intersexuality favored early surgery, with somewhat more syndrome-specific variability in XY patients. The available survey data clearly indicate that a mandatory delay of genital surgery in all patients with somatic intersexuality to the age of consent would disregard the wishes of the majority of surveyed patients. A syndrome- and syndrome severity-specific individualized approach to surgery decisions appears more appropriate.
\end{abstract}

(c) 2022 S. Karger AG, Basel

\section{Introduction}

Given the importance of reproduction for the survival of individuals, families, clans, and tribes in traditional societies, the binary system of sex and gender has dominated human societies throughout history. Somatic intersexuality (also labeled disorders of sex development [DSD] or differences of sex development [DSD] with intersex traits) as indicated by an atypical reproductive tract and/ or atypical secondary sex characteristics constitutes a challenge to the binary system and is associated with variable degrees of psychosocial stigma, although some societies have provided social niches for the small minority of individuals who do not fit the binary system [1]. The use of genital surgery to make adult individuals with genital "ambiguity" fit into the binary system in regard to genital appearance and, if possible, function, and that is usually not acutely medically necessary (often also called "corrective" or "normalizing genital surgery") dates back to at least Hellenistic and Roman antiquity [2-5]. During the second half of the 20th century, when advances in surgical techniques made it possible, such genital surgery in infancy and early childhood became a widely accepted clinical norm in Western societies, with the goals of reducing intersex-related stigma, minimizing parental anxiety, and facilitating gender development within the binary gender

\footnotetext{
Karger!"
}

Correspondence to:

Heino F.L. Meyer-Bahlburg, heino.meyer-bahlburg@nyspi.columbia.edu 
system [6]. Clinicians' reasons in support of early surgery include that infants do not need explanations and counseling, and surgeons note certain technical advantages of performing genital surgery early (e.g., [7]).

However, such surgery is technically demanding. Initial approaches frequently led to unsatisfactory cosmetic and functional outcomes in adolescence and adulthood, especially clitorectomy in female-assigned infants that usually involved lesions of the neurovascular bundle. More recent, improved techniques of genital surgery have led to better outcomes but still carry some risk $[8,9]$. An additional complication is the increased prevalence of gender dysphoria and patient-initiated gender change in patients with intersexuality compared to the nonintersex population. This was particularly marked in earlier decades, when female assignment of XY patients with intersexuality was favored, because - in the presence of a small clitorophallus - feminizing surgery seemed easier than masculinizing surgery. Subsequent long-term gender outcome studies forced a revision of that gender assignment policy [10].

With the publication of examples of unsatisfactory outcomes of initial gender assignment and associated genital surgery and the advent of intersex advocacy, the timing of such surgery relative to the age of consent has become a highly controversial topic, with diverse arguments both pro and con early surgery [11]. Based on a human rights perspective, especially respect for the patient's autonomy [12] and for the child's right to an open future [13], many ethicists and intersex activists have demanded a delay of genital surgery to the age of consent, expressed legal threats to surgeons performing such surgeries, or even called for a general moratorium on such surgery, until better outcome data are available [14-19]. In line with these critiques, the European Council Resolution 2191 (2017) calls on the Council of Europe member States "to prohibit medically unnecessary sex'normalizing' surgery, sterilization and other treatments practised on intersex children without their informed consent" [20]. Some advocacy statements have gone so far as to label such early surgery "intersex genital mutilation" or a "human rights abuse" [21]. A European working group of medical and mental-health services providers published a consensus document that includes the statement: "For sensitive and/or irreversible procedures, such as genital surgery, we advise that the intervention be postponed until the individual is old enough to be actively involved in the decision whenever possible" [22]. A German interdisciplinary consensus paper took a similar position [23], while the American Medical Associa- tion, after extensive discussions, decided against including a similar statement in its Ethics Opinion on Pediatric Decision Making [24]. Some international organizations, a few countries, and several US states have proposed or enacted legal bans of genital surgery until the patients are old enough to provide informed consent [25]. Recently, a leading children's hospital in the USA apologized for having performed early surgery on children with somatic intersexuality and adopted a policy that "irreversible genital procedures, particularly clitoroplasty, should not be performed until patients can participate meaningfully in making the decision for themselves, unless medically necessary," with the possible exception of patients with XX congenital adrenal hyperplasia (CAH) [26].

However, the argumentation of this movement against early genital surgery is conspicuously one-sided. It disregards the risk of intersex stigma associated with genital ambiguity at all stages of development and in all spheres of life, which is gradually being documented [27-32]. In addition, it disregards the data generated by surveys of samples of patients with somatic intersexuality regarding their opinions on the timing of genital surgery. The present article provides a review of such surveys.

\section{Methods}

PubMed was searched for the period January 2000-October 2021 with the phrase "disorders of sex development AND surgery." The resulting 5,318 reference titles and abstracts were screened for any indications of possible inclusion of data from surveys of individuals with intersexuality and/or their families by words such as patients', parents', or families' "views," concerns," "perspectives," or "attitudes" about/toward medical management or surgery, and the respective articles were screened for survey data on opinions regarding the timing of genital surgery. Reference selection was limited to articles in English, Spanish, French, and German. This search led to the identification of three articles reporting data from surveys of parents only [33-35], four articles including surveys of both parents and patients [25, 36-38], and four articles including surveys of patients only [39-42]. Two additional articles on surveys of patients only $[43,44]$ were accidentally identified while studying article texts during an independent search for articles on behavioral outcomes of genital surgery in individuals with intersexuality, and a further article on a patients-only survey [45] was mailed by its principal investigator to this author. The present paper is limited to data from patient surveys because it is frequently argued that early genital surgery is sought for the alleviation of parents' distress and dissatisfaction rather than for the benefits of the patients $[6,11,16,19]$. One article with data from surveys of both patients with 46,XX CAH and their parents [38] was excluded from analysis because it mostly presented the data from patients and parents combined. 


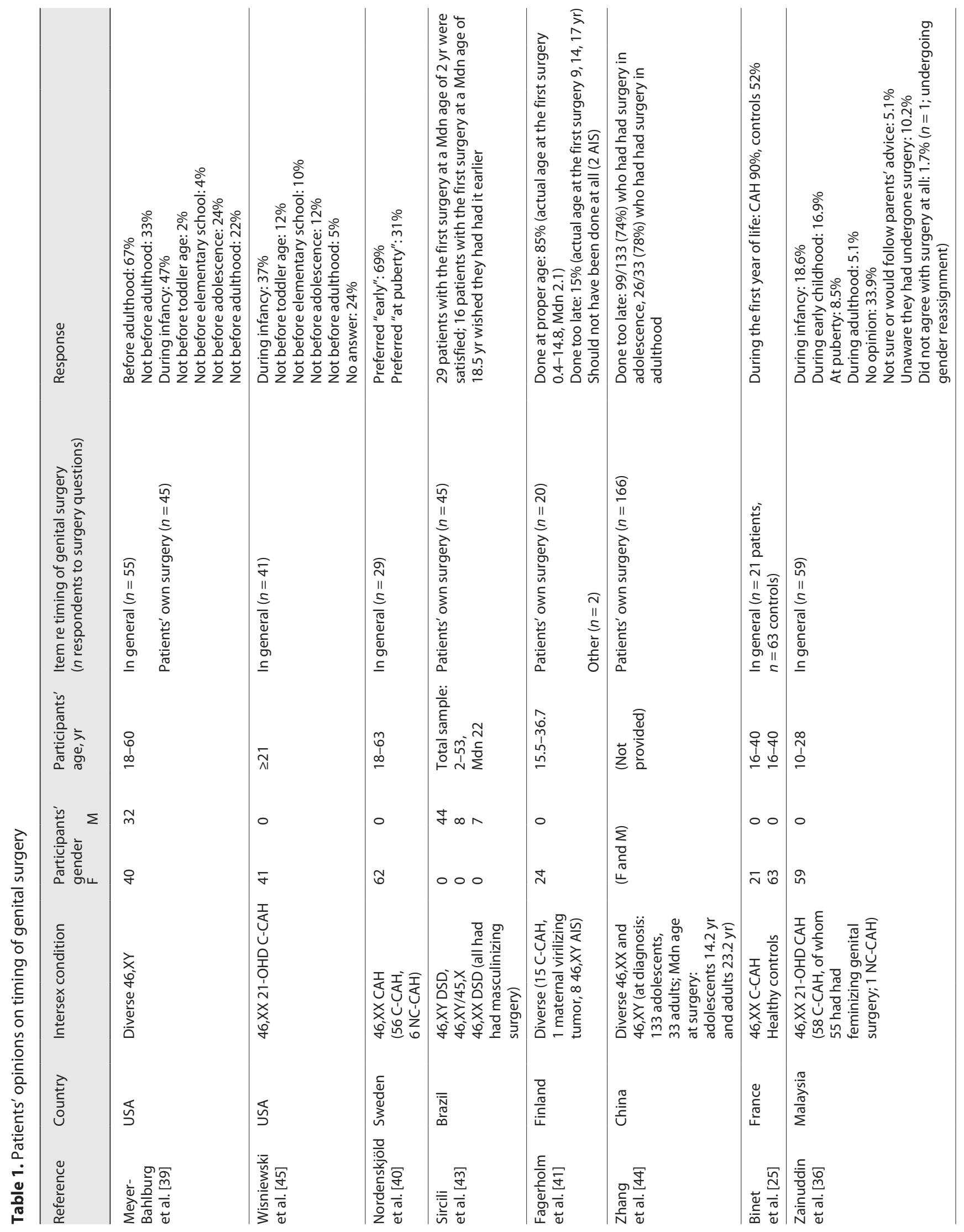




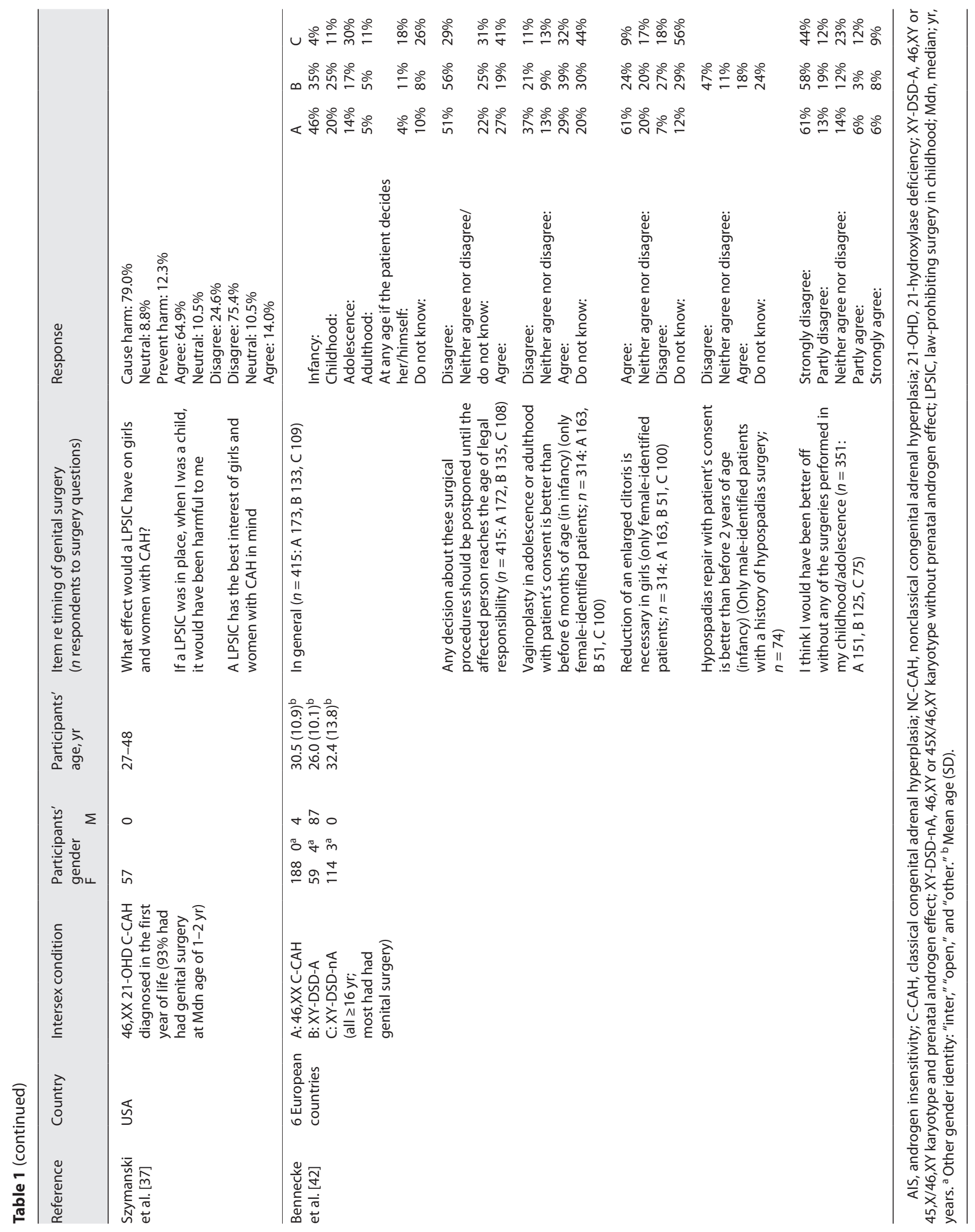




\section{Results}

Ten pertinent surveys with data from individuals with somatic intersexuality were retained (Table 1), all published in the English language: three from the USA [37, 39, 45]; four from European countries [25, 40-42]; and one each from Brazil [43], China [44], and Malaysia [36]. All 10 surveys were based on samples of clinic patients, most of whom had previously undergone genital surgery. The formulations of questions related to surgical timing varied considerably; most focused on opinions about appropriate timing of such surgery in general or specifically on opinions about the appropriate timing of the patients' own surgery.

Total sample sizes of participants answering questions regarding the timing of genital surgery ranged from $n=$ 21 to $n=415$. Five surveys were limited to women with $\mathrm{XX}$ CAH. One survey included XX women with CAH and $\mathrm{XY}$ women with androgen insensitivity, one other focused on men and women with various categories of XY intersexuality, two covered males and females with diverse $\mathrm{XX}$ and $\mathrm{XY}$ intersex syndromes, and one dealt with male-raised patients with diverse $46, \mathrm{XY}, 46, \mathrm{XY} / 45, \mathrm{X}$, and $46, \mathrm{XX}$ syndromes.

In regard to the timing of genital surgery, the clear majority of patients in seven of nine studies directly inquiring about timing preferences favored early surgery (mostly at infancy or childhood age) over later ages $(p<0.05)$ $[25,36,39-42,45]$. In the Chinese study [44], in which late clinical presentation and late surgery was prevalent, $74 \%$ of patients with surgery in adolescence and $78 \%$ of patients with surgery in adulthood thought the surgery was too late. Similarly, in the Brazilian study [43], the subgroup of patients first operated in adolescence or adulthood would have preferred earlier surgery. On the other hand, each study included a minority of patients with different preferences or uncertainty, especially patients with XY complete androgen insensitivity (CAIS) [44] and patients with XY intersexuality without prenatal androgen effects (including CAIS) [42].

The latter large-sample six-country European study [42] allows a comparison of three subgroups: (A) XX $\mathrm{CAH}$ (almost all female-identified), (B) XY-DSD with prenatal androgen effects (most either male- or femaleidentified), and (C) XY-DSD without prenatal androgen effect (almost all female-identified and none male-identified). Group A showed the strongest preference for early surgery, Group B a similar, although less clear-cut preference pattern, but the majority of Group C patients favored somewhat later surgery. Across all three groups, support group contact within the preceding 12 months (which applied to about $15 \%$ of patients) was significantly associated with an increase of preference for surgery at a later age. A question about postponing the surgery to the age of legal responsibility elicited a similar pattern of responses. If the question regarding timing preferences was focused on vaginoplasty, the response patterns were much more variable, and the group differences diminished. A clear majority of women with XX CAH endorsed the necessity of clitoral reduction, while slightly more of the female-identified patients in the other two groups disagreed than agreed with that opinion. A clear majority of male-identified patients with a history of hypospadias repair endorsed early hypospadias surgery. Finally, only a very small minority of patients in all three groups agreed that they would have been better off without having undergone any of the surgeries during childhood/adolescence. The authors note that for several questions, the responses of patients with intersexuality were somewhat associated with their own medical history, e.g., in regard to the type of genital surgery they had and its timing. Unfortunately, these associations were not controlled for the severity of the respective intersex conditions, which influence such surgery decisions.

The most recent study on women with XX CAH in the USA [37] did not directly inquire about timing preferences but asked questions about the impact of a potential law prohibiting such surgery "in childhood"; the vast majority of women with CAH agreed that such a law would cause harm. One European study [25] asked both patients and matched controls for their opinion on the timing of surgery: $90 \%$ of women with CAH versus $52 \%$ of healthy control women $(p<0.05)$ believed that genitoplasty in XX $\mathrm{CAH}$ should be performed during the first year of life.

\section{Discussion}

The salient finding of this review is that a clear majority of patients with somatic intersexuality favors genital surgery before the age of consent, particularly in infancy or early childhood. Note that these patients have personally experienced the psychosocial consequences of living with somatic intersexuality, and most of the survey participants had undergone one or more genital surgeries. Their preference for early surgery constitutes a striking contrast to the human rights-based demands for surgery delay by ethicists and politicians who usually do not have that lived experience and who may be more comparable to nonintersex survey controls from the general public in
Meyer-Bahlburg 
the French study [25], whose support for early surgery was less strong. Thus, the preference of the majority of patients is incompatible with a legal ban of such surgery before the age of consent and does also not support a general moratorium of early surgery.

This finding is particularly surprising for patients with $\mathrm{XY}$ intersexuality, given that the delay of medically unnecessary genital surgery is demanded primarily by intersex advocates with XY conditions as well as by past and present support and advocacy groups that focus on patients with XY intersexuality, e.g., the Intersex Society of North America (now inactive) or the androgen insensitivity Support Group (recently merged into the InterCONNECT organization). It raises the question to which extent advocates, who are usually not elected, really represent the opinion of their community as a whole. The finding is less surprising for patients with XX CAH since the major support organization for CAH, the CARES Foundation [46], as well as its analog in other countries, as for instance the CAH Parents' and Patients' Group in Germany [23, Appendix], advocates a position distinctly different from that of the XY support and advocacy groups.

In this context, it is important to keep in mind the diversity of intersex presentations. Women with XX CAH experience a congruence of their gender with their sexual karyotype, gonads, gonadal hormones, and internal reproductive tract, and, with appropriate medical care, most will be able to get pregnant and give birth. With the institution of neonatal screening programs for $\mathrm{CAH}$ in resource-rich societies, such newborns are diagnosed early, recognized as biological females, assigned to the female gender, and medically treated accordingly so that patient-initiated gender reassignment later is rare.

Patients with XY intersexuality are much more diverse. Those with the most extreme degree of hypo-androgenization (e.g., CAIS or complete gonadal dysgenesis) are frequently assumed to be biological females at birth, assigned to the female gender, and may not be diagnosed before the age of puberty. Markedly hypo-androgenized newborns who are diagnosed at birth are also likely to be assigned female. In adolescence and adulthood, both subgroups are likely to live with the knowledge of the incongruence of their female role with their sexual karyotype, gonads, gonadal hormones (if produced at all), and possibly internal reproductive structures; in addition, pregnancy and childbirth are usually not possible. A further complication is the variable risk of gonadal malignancy development in such patients, which may lead to gonadectomy regardless of gender assignment [47]. It is not surprising therefore that such patients may have developed a private gender identity that is more nuanced, e.g., a variant of "nonbinary," than female in the usual sense [48, 49]. Moreover, gonadectomized women with CAIS have reduced sexual satisfaction and increased psychological distress, which presents a challenge to adequate hormone replacement therapy [50]. XY women with rare conditions such as $5 \alpha$-reductase- 2 deficiency or $17 \beta$-hydroxysteroid-dehydrogenase-3 deficiency may start marked body virilization in puberty, which is associated with an increased probability of strong gender dysphoria and patient-initiated gender reassignment [51]. Given this diversity of initial presentations and of developmental trajectories, it is not surprising that patients with XY intersexuality tend to show a somewhat greater diversity in opinions regarding the timing of gender-affirming genital surgery than women with XX CAH.

In any case, both XX and XY individuals with somatic intersexuality include a minority who are not in favor of early surgery, which presents an ethical dilemma for guideline development. Unfortunately, the surveys that have been conducted to date lack systematic assessments of the reasons or motivations of patients' preferences for early versus later surgery. The still very limited literature on intersex stigma cited earlier suggests that stigma risk constitutes a major reason for patients' preference for early surgery. Others may be dissatisfied with the esthetic or functional outcome of the surgery, especially when they were treated with earlier, now obsolete surgical techniques like clitorectomy. For patients who later develop severe gender dysphoria and initiate gender reassignment, the early surgery performed to align the genital appearance with the initially assigned gender turns out to be really incongruent with the later gender identity, especially when the surgery is aimed at feminization, which is very difficult to undo.

As to guideline development, several considerations emerge from this review and from the status of the evidence generally as follows: (1) it is important to optimize initial gender assignment so that the risk of later severe gender dysphoria and patient-initiated gender reassignment is minimized; in this regard, the international conference on intersex management in 2005 has led to considerable progress [10]; see also [51, 52]. (2) Given the diversity of intersex syndromes and their variations in severity, a one-fits-all approach to the timing of genital surgery is inappropriate; neither a total ban of early surgery nor early surgery for all are advisable. Instead, an individualized approach is needed that takes into consideration the available outcome data from the diverse intersex syndromes, uses current evidence for the syndrome-spe- 
cific assessment of gonadal malignancy risk in decisions on gonadectomy [53,54], and involves the provision of detailed information on the pros and cons of early versus delayed surgery in preparation for fully informed consent by the parents (and later the patients, when cognitively sufficiently developed). This is the position that key endocrine and urology societies and experts have adopted in recent years [7, 55-57]. (3) In XY patients with moderate degrees of genital hypo-masculinization at birth, where long-term gender outcome is uncertain, a delay of genital surgery, especially "feminization," appears indicated, at least until gendered behavior and gender identity can be clearly assessed - usually not earlier than at about age 5-6 years, provided the child has sufficient exposure to both male and female playmates. If at that age, gendered behavior and/or identity is markedly atypical for the assigned gender, genital surgery should be delayed further. (4) Also, note that genital surgery is not recommended any more for mild degrees of syndrome severity [10].

In view of an apparently increasing societal openness to a nonbinary gender system, an editorial reviewer of this article raised the question "whether (experienced or feared) stigmatization can and should serve as a sufficient justification for such a serious, irrevocable, and low-evidence based intervention." My answer is that, in the USA at least, this increasing openness is far from universal, with major differences between regions, social classes, and religious and political ideologies. At this time, there is no guarantee that this openness will become universal. In my clinical experience, most children with intersexuality want to be one of the binary genders. Also, most adolescent and adult patients with intersexuality appear to publicly adopt one of the two binary gender roles, even if they privately identify as nonbinary. Moreover, intersex stigma remains strong. Thus, I think professionals need to await genuine lasting changes in patients' opinions and views on this issue before they impose a general ban on early genital surgery.

Given the ongoing controversy about the timing of genital surgery, the strength of this set of surveys is that they, in aggregate, include a sizeable number of diverse patients with intersexuality. From a strictly methodological standpoint however these survey studies still leave much to be desired. They used clinical convenience samples, often including only a fraction of the eligible patients seen in a clinic. For instance, the European six-country dsd-LIFE project managed to include only $36.1 \%$ of the eligible patient samples in the overall project (which also includes patients with Turner syndrome or Klinefelter syndrome), and not all of its participants with somatic intersexuality answered the online survey questions regarding surgery timing preferences. This raises the question of representativeness and potential selection biases. Reasons for nonparticipation may include patients' move without leaving a forwarding address; schedule conflicts in studies involving face-to-face meetings; survey fatigue, especially in internet-based or postal-questionnairebased studies, given the expanding frequency of such survey requests in many spheres of life; and dissatisfaction with the medical care received. On the other hand, the consistency of results across countries, survey formats, and studies with either low or very high participation rates make it likely that the main findings are valid.

Future research should also systematically inquire about the specific reasons underlying patients' preferences for early versus late surgery. In addition, long-term follow-up studies of outcomes of gender assignment and associated genital surgery - with patients categorized by syndrome and with syndrome severity and surgery techniques clearly described - are urgently needed for further refinement of treatment guidelines.

\section{Conclusions}

The published surveys of the opinion of patients with somatic intersexuality regarding the timing of genital surgery show that the majority favor early surgery. Thus, a mandatory delay of genital surgery to the age of consent disregards the preferences of the majority of such patients and, thereby, constitutes a violation of medical ethics.

\section{Acknowledgments}

Ms. Tonya Reid-Kim assisted in the construction of the tables.

\section{Conflict of Interest Statement}

The author has no conflicts of interest to declare.

\section{Funding Sources}

The author did not receive any funding for this study.

\section{Author Contributions}

Conceptualization and literature review were done exclusively by the author.
Meyer-Bahlburg 


\section{References}

1 Meyer-Bahlburg HFL. "Diagnosing" gender? Categorizing gender-identity variants in the anthropocene. Arch Sex Behav. 2019 Oct; 48(7):2027-35.

2 Lascaratos J, Kostakopoulos A. Operations on hermaphrodites and castration in Byzantine times (324-1453 AD). Urol Int. 1997;58(4): $232-5$.

3 Gurunluoglu R, Gurunluoglu A. Paulus Aegineta, a seventh century encyclopedist and surgeon: his role in the history of plastic surgery. Plast Reconstr Surg. 2001 Dec;108(7):2072-9.

4 Markantes GK, Deligeoroglou E, Armeni AK, Vasileiou V, Damoulari C, Mandrapilia A, et al. Callo: the first known case of ambiguous genitalia to be surgically repaired in the history of medicine, described by Diodorus Siculus. Hormones. 2015 Jul-Sep;14(3):459-61.

5 Büyükünal C, Zeller KA, Emre S, Nakayama DK. The history of surgery in disorders of sexual development. J Pediatr Surg. 2020 Feb; 36(2):113-27.

6 Crawford JM, Warne G, Grover S, Southwell BR, Hutson JM. Results from a pediatric surgical centre justify early intervention in disorders of sex development. J Pediatr Surg. 2009 Feb;44(2):413-6.

7 Speiser PW, Arlt W, Auchus RJ, Baskin LS, Conway GS, Merke DP, et al. Congenital adrenal hyperplasia due to steroid 21-hydroxylase deficiency: an Endocrine Society clinical practice guideline. J Clin Endocrinol Metab. 2018 Nov;103(11):4043-88.

8 Kreukels BPC, Cohen-Kettenis PT, Roehle R, van de Grift TC, Slowikowska-Hilczer J, Claahsen-van der Grinten H. Sexuality in adults with differences/disorders of sex development (DSD): findings from the dsd-LIFE study. J Sex Marital Ther. 2019;45(8):688705.

9 Rapp M, Duranteau L, van de Grift TC, Schober J, Hirschberg AL, Krege S, et al. Selfand proxy-reported outcomes after surgery in people with disorders/differences of sex development (DSD) in Europe (dsd-LIFE). J Pediatr Urol. 2021 Jun;17(3):353-65.

10 Hughes IA, Houk C, Ahmed SF, Lee PA; Lawson Wilkins Pediatric Endocrine Society (LWPES)/European Society for Pediatric Endocrinology (ESPE) Consensus Group. Consensus statement on management of intersex disorders. Arch Dis Child. 2006 Jul;91(7): 554-63.

11 Wisniewski AB, Tishelman AC. Psychological perspectives to early surgery in the management of disorders/differences of sex development. Curr Opin Pediatr. 2019 Aug;31(4): $570-4$.

12 Belmont report. 1979 [cited 2021 Jun 3]. Available from: http://www.hhs.gov/ohrp/ regulations-and-policy/belmont-report/ read-the-belmont-report/index.html.

13 Kon AA. Ethical issues in decision-making for infants with disorders of sex development. Horm Metab Res. 2015 May;47(5):340-3.
14 Greenberg JA. International legal developments protecting the autonomy rights of sexual minorities. In: Sytsma SE, editor. Ethics and intersex. Dordrecht: Springer; 2006. p. 87-101.

15 Ittelson A, Tamar-Mattis A. Avoiding liability in the treatment of intersex patients. J Pediatr Urol. 2016 Dec;12(6):439-40.

16 Newbould M. When parents choose gender: intersex, children, and the law. Med Law Rev. Autumn 2016;24(4):474-96.

17 Reis E. Did bioethics matter? A history of autonomy, consent, and intersex genital surgery. Med Law Rev. 2019 Nov;27(4):658-74.

18 Carpenter M. Intersex human rights, sexual orientation, gender identity, sex characteristics and the Yogyakarta principles plus 10 . Cult Health Sex. 2021 Apr;23(4):516-32.

19 Wiesemann C, Ude-Koeller S, Sinnecker GH, Thyen U. Ethical principles and recommendations for the medical management of differences of sex development (DSD)/intersex in children and adolescents. Eur J Pediatr. 2010 Jun;169(6):671-9.

20 European Council resolution 2191. Promoting the human rights of and eliminating discrimination against intersex people. 2017. Available from: europarl.europa.eu/doceo/ document/TA-8-2019-0128_EN.pdf.

21 Earp BD. Zero tolerance for genital mutilation: a review of moral justifications. Curr Sex Health Rep. 2020;12(4):276-88.

22 Cools M, Nordenström A, Robeva R, Hall J, Westerveld P, Flück C, et al. Caring for individuals with a difference of sex development: a consensus statement. Nat Rev Endocrinol. 2018 Jul;14(7):415-29.

23 Krege S, Eckoldt F, Richter-Unruh A, Köhler B, Leuschner I, Mentzel HJ, et al. Variations of sex development: the first German interdisciplinary consensus paper. J Pediatr Urol. 2019 Apr;15(2):114-23.

24 American Medical Association. Pediatric decision making. 2021 [cited 2021 Jun 3]. Available from: https://www.ama-assn.org/delivering-care/ethics/pediatric-decision-making/.

25 Binet A, Lardy H, Geslin D, Francois-Fiquet C, Poli-Merol ML. Should we question early feminizing genitoplasty for patients with congenital adrenal hyperplasia and XX karyotype? J Pediatr Surg. 2016 Mar;51(3):465-8.

26 Intersex care at Lurie Children's and our sex development clinic. 2020 [cited 2021 Jun 3 https: //www.luriechildrens.org/en/blog/intersex-care-at-lurie-childrens-and-our-sexdevelopment-clinic/.

27 Ediati A, Juniarto AZ, Birnie E, Okkerse J, Wisniewski A, Drop S, et al. Social stigmatization in late identified patients with disorders of sex development in Indonesia. BMJ Paediatr Open. 2017 Oct;1(1):e000130.
28 Meyer-Bahlburg HF, Reyes-Portillo JA, Khuri J, Ehrhardt AA, New MI. Syndrome-related stigma in the general social environment as reported by women with classical congenital adrenal hyperplasia. Arch Sex Behav. 2017 Feb;46(2):341-51.

29 Meyer-Bahlburg HFL, Khuri J, Reyes-Portillo J, New MI. Stigma in medical settings as reported retrospectively by women with congenital adrenal hyperplasia (CAH) for their childhood and adolescence. J Pediatr Psychol. 2017 Jun;42(5):496-503.

30 Meyer-Bahlburg HFL, Khuri J, Reyes-Portillo J, Ehrhardt AA, New MI. Stigma associated with classical congenital adrenal hyperplasia in women's sexual lives. Arch Sex Behav. 2018 May;47(4):943-51.

31 Joseph AA, Kulshreshtha B, Shabir I, Marumudi E, Sam George T, Sagar R, et al. Gender issues and related social stigma affecting patients with a disorder of sex development in India. Arch Sex Behav. 2017 Feb;46(2):361-7.

32 Rolston AM, Gardner M, Vilain E, Sandberg DE. Parental reports of stigma associated with child's disorder of sex development. Int J Endocrinol. 2015;2015:980121.

33 Dayner JE, Lee PA, Houk CP. Medical treatment of intersex: parental perspectives. J Urol. 2004 Oct;172:1762-5.

34 Marei MM, Fares AE, Musa N, Abdelsattar AH, Sharaf A, Hassan MM, et al. Timing and outcome concerns regarding feminizing genitoplasty from the perspective of Egyptian families of girls with virilized external genitalia. Horm Res Paediatr. 2016 Jul;85:49-57.

35 Szymanski KM, Whittam B, Kaefer M, Frady H, Casey JT, Tran VT, et al. Parental decisional regret and views about optimal timing of female genital restoration surgery in congenital adrenal hyperplasia. J Pediatr Urol. 2018;14:156.e1-e7.

36 Zainuddin AA, Crover SR, Soon CH, Ghani NAA, Mahdi ZA, Manaf MRA, et al. A multicenter cross-sectional study of Malaysian females with congenital adrenal hyperplasia: their body image and their perspectives on feminizing surgery. J Pediatr Adolesc Gynecol. 2020 Oct;33(5):477-83.

37 Szymanski KM, Braga LH, Whittam B, Kokorowski P, Leland BD; on behalf of the Life with Congenital Adrenal Hyperplasia Study Group. What do patients and parents say about parents' ability to choose early genital surgery for girls with congenital adrenal hyperplasia? J Urol. 2021 Jun;205(6):1770-7.

38 Shalaby M, Chandran H, Elford S, Kirk J, McCarthy L. Recommendations of patients and families of girls with 46XX congenital adrenal hyperplasia in the United Kingdom regarding the timing of surgery. Pediatr Surg Int. 2021 Jan;37(1):137-43.

39 Meyer-Bahlburg HF, Migeon CJ, Berkovitz GD, Gearhart JP, Dolezal C, Wisniewski AB. Attitudes of adult 46, XY intersex persons to clinical management policies. J Urol. 2004 Apr;171(4):1615-9. 
40 Nordenskjöld A, Holmdahl G, Frisén L, Falhammar H, Filipsson $\mathrm{H}$, Thorén M, et al. Type of mutation and surgical procedure affect long-term quality of life for women with congenital adrenal hyperplasia. J Clin Endocrinol Metab. 2008 Feb;93(2):380-6.

41 Fagerholm R, Santtila P, Miettinen PJ, Mattila A, Rintala R, Taskinen S. Sexual function and attitudes toward surgery after feminizing genitoplasty. J Urol. 2011 May;185(5):19004.

42 Bennecke E, Bernstein S, Lee P, van de Grift TC, Nordenskjöld A, Rapp M, et al. Early genital surgery in disorders/differences of sex development (DSD). Patients' perspectives. Arch Sex Behav. 2021 Apr;50:913-23.

43 Sircili MH, de Queiroz e Silva FA, Costa EMF, Brito VN, Arnhold IJ, Dénes FT, et al. Longterm surgical outcome of masculinizing genitoplasty in large cohort of patients with disorders of sex development. J Urol. 2010 Sep; 184(3):1122-7.

44 Zhang H, Pan J, Ji H, Wang Y, Shen W, Liu L, et al. Long-term evaluation of patients undergoing genitoplasty due to disorders of sex development: results from a 14-year follow-up. Sci World J. 2013 Nov;2013:298015.

45 Wisniewski AB, Migeon CJ, Malouf MA, Gearhart JP. Psychosexual outcome in women affected by congenital adrenal hyperplasia due to 21-hydroxylase deficiency. J Urol. 2004 Jun;171(6 Pt 1):2497-501.

46 CARES Foundation. Statement on surgery. 2021 [cited 2021 Jun 6]. Available from: https: //www.caresfoundation.org/treatment/surgery/.
47 Slowikowska-Hilczer J, Szarras-Czapnik M, Duranteau L, Rapp M, Walczak-Jedrzejowska $\mathrm{R}$, Marchlewska K, et al. Risk of gonadal neoplasia in patients with disorders/differences of sex development. Cancer Epidemiol. 2020 Dec;69:101800.

48 Brinkmann L, Schweizer K, Richter-Appelt $\mathrm{H}$. Geschlechtsidentität und psychische Belastungen von erwachsenen personen mit Intersexualität [Transl.: Gender identity and psychological stress of adult persons with intersexuality]. Z Sex Forsch. 2007;20:129-44.

49 Kreukels BPC, Köhler B, Nordenström A, Roehle R, Thyen U, Bouvattier C, et al. Gender dysphoria and gender change in disorders of sex development/intersex conditions: results from the dsd-LIFE study. J Sex Med. 2018 May; 15(5):777-85.

50 Birnbaum W, Marshall L, Werner R, Kulle A, Holterhus P-M, Rall K, et al. Oestrogen versus androgen in hormone-replacement therapy for complete androgen insensitivity syndrome: a multicentre, randomised, doubledummy, double-blind crossover trial. Lancet Diabetes Endocrinol. 2018 Oct;6(10):771-80.

51 Babu R, Shah U. Gender identity disorder (GID) in adolescents and adults with differences of sex development (DSD): a systematic review and meta-analysis. J Pediatr Urol. 2021 Feb;17(1):39-47.
52 Ernst MM, Kogan BA, Lee PA. Gender identity: a psychosocial primer for providing care to patients with a disorder/difference of sex development and their families [Individualized care for patients with intersex (disorders/ differences of sex development): part 2]. J Pediatr Urol. 2020 Oct;16(5):606-11.

53 Spoor JA, Oosterhuis JW, Hersmus R, Biermann K, Wolffenbuttel KP, Cools M, et al. Histological assessment of gonads in DSD: relevance for clinical management. Sex Dev. 2018;12(1-3):106-22.

54 Looijenga LHJ, Kao CS, Idrees MT. Predicting gonadal germ cell cancer in people with disorders of sex development; insights from developmental biology. Int J Mol Sci. 2019 Oct;20(20):5017.

55 Stark T, Shoag JE, Poppas DP. Eliminating early surgery for disorders of sex development: risking adverse outcomes in 46,XX CAH. J Urol. 2019 May;201(5):871-3.

56 Pediatric Endocrine Society. Position statement on genital surgery in individuals with differences of sex development (DSD)/intersex traits (care guidelines consensus statement). 2020 Oct 20 [cited 2021 Jun 6]. Available from: https://mk0pesendoklgy8upp97. kinstacdn.com/wp-content/uploads/2020/ 10/44-DSDpaperPosition-Statement-DSDSIG.pdf.

57 Bangalore Krishna K, Kogan BA, Mazur T, Hoebeke P, Bogaert G, Lee PA. Individualized care for patients with intersex (differences of sex development): part 4/5. Considering the Ifs, Whens, and Whats regarding sexual-reproductive system surgery. J Pediatr Urol. 2021 Jun;17(3):338-45. 